\title{
The Epidemiological, Therapeutic and Evolutionary Profile of Breast Medullary Carcinoma
}

\author{
J Achrane $\mathrm{H}^{1 *}$, Asmouki ${ }^{1}$ and M Khouchani ${ }^{2}$ \\ ${ }^{1}$ Gynecology service, Mother and Child Hospital. Mohamed VI Teaching Hospital, Morocco \\ ${ }^{2}$ Oncology department, Mother and Child Hospital. Mohamed VI Teaching Hospital, Morocco
}

Submission: December 02, 2019; Published: January 21, 2020

"Correspondence Author: J Achrane H, Gynecology service, Mother and Child Hospital, Mohamed VI Teaching Hospital, Morocco

\begin{abstract}
Breast Medullary carcinoma is a histologic form with inflammatory stroma requiring strict histological criteria for its definition (RIDOLFI 1977). It represents less than $5 \%$ of breast tumors. The aim of this work is to analyse the epidemiological, clinical, evolutive characteristics and therapeutic results, through a retrospective study of medullary breast carcinoma histologically confirmed and treated in the oncology department of the university hospital of Marrakech city during a period of five years, from 2007 to 2012.17 cases of medullary carcinoma were collected as $2.2 \%$ of breast cancers treated during the same period. The average age was 47 years (30-58 years). The average tumor size was 4 $\mathrm{cm}$ with axillary lymph nodes in 6 cases (35\%). The common site was the upper outer quadrant in $47 \%$ of cases. 30\% of cases showed a typical medullary carcinoma. And estrogenic or progesterone hormone receptors were negative in 9 cases (52\%) and HER negative in 5 patients (47\%). All typical carcinomas were "triple negative". Conservative surgery was performed in $47 \%$ of cases, while a total mastectomy with lumpectomy involved $53 \%$ of the remaining patients. Chemotherapy was administered in $88 \%$ of patients. Postoperative radiotherapy was performed in $94 \%$ of cases. $35 \%$ of patients had received adjuvant hormonal therapy, two patients had received targeted therapy. With a median follow of 25 months, only one case of recurrence was reported, no cases of metastasis or death was noted. This study confirms the favourable evolution of the medullary breast cancer despite poor prognostic factors often found in these rare tumors
\end{abstract}

Keywords: Breast Medullary carcinoma; Typical breast Medullary carcinoma; Favorable outcomes

\section{Introduction}

Tissue pulp is a type of breast tissue in stroma that requires strict identification criteria (Redolphy 1977). This type of breast cancer represents less than $5 \%$. The study analyzed clinical, histological and also therapeutic indicators by reviewing our center experience. Our work is a preparatory study of the Center for Pulmonary Breast Cancer Oncological University Hospital in Marrakech over a period of 5 years from 2007 to 2012 in 17 cases representing $2.2 \%$ of the total breast cancers. Average The age of patients reached 47 years. The average tumor size was $4 \mathrm{~cm}$ with lymph node injury in 6 cases equivalent to $35 \%$. The tumor is concentrated in the upper outer quadrant by Typical pulp cancer accounts for $47 \%$ of cases. Hormonal receptors were negative in 9 cases (52\%) and human skin growth factor receptors

It was negative in 5 cases (47\%) while all typical pulp cancers were "triple negative". Conservative surgery was performed on $47 \%$ of cases. While been Total mastectomy with axillary lymph nodes in $53 \%$ of the remaining cases. $88 \%$ of patients benefited from chemotherapy. $94 \%$ of the cases were treated Radiological.
Also, 35\% of patients received hormone therapy while two of them received targeted therapy. The average follow-up rate was equivalent to 25 months. Through The progression of the disease was observed topical repercussions in one patient without death. This study confirms that endodontic breast cancer retains positive outcome contrasting with histological indicators Bad.

The medullary carcinoma $(\mathrm{CM})$ breast is a rare histological form, it represents less than $5 \%$ of all breast cancers. Its clinical and radiological aspect is often suggestive of benignity hence the delay of diagnosis. The prognosis is better compared to other invasive cancers. In our study we report a series of 17 cases of medullary breast carcinoma collected at the Oncology Department Mohamed VI Hospital of Marrakech. The purpose of our work is to relate our experience in this particular histological type of breast cancer with a review of the literature.

\section{Material and Methods}

This is a retrospective study of 17 patients treated in the Oncology Department at Mohamed VI University Hospital. 
Marrakech, for a period of five years, from 2008 to 2012. The epidemiological, therapeutic and evolutionary data were collected on a pre-established exploitation sheet. All cases of breast cancer, followed in the Oncology department, were reviewed and only histologically confirmed spinal cord carcinomas were selected. Overall survival could not be calculated due to insufficient followup (25 months) and the small number of patients, only the median survival was determined.

\section{Results}

During our study period, 2839 women with breast cancer were recruited to the oncology department of Mohammed VI Hospital, Marrakesh.17 cases had histologically confirmed breast carcinoma of the breast, a proportion of $2.2 \%$. Patient age was 47 years old with extremes of 30-58 years old. The age group between 40 and 55 years was the most represented with $70 \%$ of cases $64 \%$ of women were menopausal. Family history research found that two patients had a family history of breast cancer, with the sister in one case and the maternal aunt in the other. The average consultation time was on average 7 months. This delay was less than 6 months in $94 \%$ of cases. The perception of a breast nodule was the reason for consultation in all our patients, associated in one case with mastodynies. The left breast was affected in $64 \%$ of cases, with predominance at the super-external headquarters in 8 cases $(47 \%)$.

There was no case of bilaterality. The average tumor size was $4 \mathrm{~cm}$. The examination did not find fixity of this nodule in the deep plane. On the other hand, a mammalian flow was found in a single patient with a mucosal aspect at the pressure of the nipple. The ipsilateral axilla was the site of suspected lymphadenopathy in 6 cases. The rest of the general examination for possible secondary localization was completely normal. Mammography was performed in all patients preoperatively. It found an opacity of benign appearance in $59 \%$ of cases, and a strongly suspect appearance in $41 \%$ of cases, with no microcalcifications.

An ultrasound complement consolidated the diagnosis of benign nodule in $59 \%$ of cases and suspicious nodule in $41 \%$ of cases. The diagnosis of certainty was carried out in ten patients on a biopsy with extemporaneous examination. Six patients had been subjected to a microbiopsy before the surgical procedure while and the open biopsy in only one case. Chest X-ray and abdominopelvic ultrasound as a extension assessment have not objectified secondary locations. According to the TNM 2010 classification, the T2N0 stage was the most frequent followed by the T1N0 also testifying to the localized stage of these medullary carcinomas. Subject to bone scans, all our patients were classified as M0.

All our patients were operated on. The local surgical procedure consisted of a radical mastectomy in 9 cases (53\%) and a lumpectomy in $8(47 \%)$. Lumpectomy was performed in patients whose tumor size was less than or equal to $3 \mathrm{~cm}$. Axillary ipsilateral dissection was performed in all patients. The surgical procedure was preceded by neoadjuvant chemotherapy in 2 patients whose tumor was classified as T4bN0M0 and T4CN1M0. The analysis of the operative specimen made it possible to determine certain prognostic parameters. The average anatomical tumor size was $4 \mathrm{~cm}$ with extremes of $1.5-8 \mathrm{~cm}$. The peritumoral vascular emboli were present in only one case, concerning the histological type, it was a typical medullary carcinoma in $30 \%$ of the cases and atypical $70 \%$ of the cases. The determination of the hormonal receptors was Negative in 9 cases and positive in the others, and HER2 negative in 5 patients (45\%). It should be noted that the HER2 study was not performed in 6 patients. Regarding combinations of HER2 status and HR status: 3 tumors were "triple negative" with hormone receptors and HER2 negative status.

They were all typical medullary carcinomas. The average number of lymph nodes removed during the cleaning was 14 lymph nodes. The lymphadenectomy consisted of 10 or more lymph nodes (sufficient lymphadenectomy) in 16 of the cases, or $94 \%$, whereas it was considered insufficient for 8 lymph nodes in a single patient. Histological analysis revealed lymph node involvement in 7 patients. Sixteen patients (94\%) received postoperative external radiotherapy. The average time between surgery and the onset of RTH was 120 days with extremes of 50 to 240 days.

Local radiotherapy was performed on the breast or the wall at the dose of $50 \mathrm{~Gy}$ and on the ganglion areas at the dose of 46 Gy. The interstitial brachytherapy was carried out postoperatively and after the external radiotherapy in a patient having benefited from a conservative treatment as a dose supplement at the level of the tumor bed. Chemotherapy (CT) was administered to 15 patients (88\%). The protocol was based on anthracyclines in 11 cases and taxanes in 4 patients (24\%). It has been indicated in patients with axillary lymph node involvement and in patients with tumor size greater than one centimetre and younger than 40 years of age. Each patient received 6 courses of chemotherapy. The interval between treatments was on average 21 days. Six patients (35\%) with hormone receptor positive status, including 4 postmenopausal patients, received adjuvant adjuvant hormone therapy with Tamoxifen at a dose of $20 \mathrm{mg} / \mathrm{d}$ for a five-year period, rather than missed antiaromatases. means.

At the end of the therapeutic sequence, 12 patients (70\%) were regularly followed the end of adjuvant treatment, with a $100 \%$ local control rate. The median follow-up was 25 months with extremes ranging from 5 to 120 months. No deaths were reported. Given the low number of patients, we stopped at the calculation of the average survival, which was 3 years, with an average survival of 3 years without recurrence of $94 \%$. The table below includes all the characteristics studied in our series (Table 1). 


\section{Cancer Therapy \& Oncology International Journal}

Table 1: Characteristics studied in the series.

\begin{tabular}{|c|c|c|}
\hline Characteristics & Name / [Total = 17] & Percentage $(\%) /[$ Total $=100 \%]$ \\
\hline \multicolumn{3}{|l|}{ Age } \\
\hline$>47$ ans & 6 & 36 \\
\hline$<47$ ans & 11 & 64 \\
\hline \multicolumn{3}{|l|}{ Statut HER2 } \\
\hline Positive & 5 & 30 \\
\hline Negative & 6 & 35 \\
\hline unknown & 6 & 35 \\
\hline \multicolumn{3}{|l|}{ Hormone Receptors } \\
\hline \multicolumn{3}{|l|}{ RP status } \\
\hline Negative & 8 & 47 \\
\hline \multicolumn{3}{|l|}{ RE status } \\
\hline Negative & 8 & 47 \\
\hline Positive & 9 & 53 \\
\hline \multicolumn{3}{|l|}{ Tumor size } \\
\hline$<4 \mathrm{~cm}$ & 6 & 36 \\
\hline$>4 \mathrm{~cm}$ & 11 & 64 \\
\hline \multicolumn{3}{|l|}{ Histological type } \\
\hline CMA & 12 & 70 \\
\hline CMT & 5 & 30 \\
\hline \multicolumn{3}{|l|}{ Lymph Node Status } \\
\hline 0 & 10 & 59 \\
\hline $3-4$ & 3 & 17 \\
\hline$>4$ & 0 & 0 \\
\hline \multicolumn{3}{|l|}{ Surgery } \\
\hline Curator & 8 & 47 \\
\hline radical & 9 & 53 \\
\hline WITHOUT & 0 & 0 \\
\hline \multicolumn{3}{|l|}{ Radiotherapy } \\
\hline External radiotherapy alone & 16 & 88 \\
\hline Brachytherapy + radiotherapy & 1 & 6 \\
\hline $\begin{array}{l}\text { External } \\
\text { Without }\end{array}$ & 1 & 6 \\
\hline \multicolumn{3}{|l|}{ Chemotherapy } \\
\hline anthracyclines & 11 & 73 \\
\hline Taxanes & 4 & 27 \\
\hline Without & 0 & 0 \\
\hline Hormone & & \\
\hline
\end{tabular}




\section{Cancer Therapy \& Oncology International Journal}

\begin{tabular}{|c|c|c|}
\hline Anti-estrogen & 6 & 35 \\
\hline Aromatase & 0 & 05 \\
\hline Without & 11 & 12 \\
\hline Targeted Therapy & 2 & 0 \\
\hline Trastuzumab & 0 & 88 \\
\hline Other & 15 & 0 \\
\hline Without & & 100 \\
\hline Remote Metastasis & 0 & 17 \\
\hline Yes & 17 & 0 \\
\hline No & & \\
\hline
\end{tabular}

\section{Discussion}

The medullary carcinoma is a particular variety of ductal cancers, requiring for its definition, histological criteria strict rules that have been studied in detail by RIDOLFI [1]. Its frequency is very poorly estimated, it would be less than $5 \%$ of all breast cancers [2]. In our series, medullary carcinoma accounted for $2.2 \%$ of breast cancers. The average age of occurrence of medullary carcinoma is 44 years [3]. Ridolfi has shown that the association of medullary carcinoma of the breast and a family history is seen in $14 \%$ of cases [1]. Clinically, the medullary carcinoma of the breast is generally a unilateral mass, notably localized in the supero-external quadrant, rounded, well limited, mobile evoking a benign formation, of size between 10 to $90 \mathrm{~mm}[3,4]$, whereas bilateral involvement is very rare [5]. In our series, the right breast was reached in $64 \%$ of the cases and the QSE in $47 \%$ of the cases. Mammography, CM can take several aspects, most often it is a well-rounded opacity evoking a benign tumor such as adenofibroma [6].

The medullary carcinoma is usually expressed in echography by a mass without calcification [4]. The medullary carcinoma is described in the literature as a solid hypoechogenic solid formation in $56 \%$ of the cases, oval or round in $81 \%$ of the cases, well circumscribed in $31 \%$ cases [7]. Histopathologically, bone marrow carcinoma is defined by the WHO as a well-defined carcinoma composed of poorly differentiated cells with a weak stroma and predominant lymphoid infiltration [8].

Histologically, there are two types of medullary carcinoma: the typical and the atypical. The typical medullary carcinoma is defined by 5 obligatory histological criteria called Ridolfi [1]: Complete peripheral histological limitation, syncitial architecture on at least $75 \%$ of the tumor surface, diffuse mononuclear inflammatory stroma, moderate or major nuclear atypia, absence of glanduliform differentiation and / or intraductal component. Atypical carcinoma atypical requires a syncitial architecture with 2 or 3 criteria only raised. For most authors, the treatment of bone marrow carcinoma does not differ from that of other breast cancers [2]. The surgical procedure and its complications are identical to those of non-medullary breast carcinoma in general According to several studies the rate the indication of conservative treatment in the surgical treatment of medullary carcinoma varies from one study to another between $4 \%$ according to Cao et al. [9] at $65 \%$ in the series of Park et al. [3] the typical medullary carcinoma does not show an extension of tumor cells inside the breast, unlike atypical medullary carcinoma where this extension is found is found in $17 \%$ of cases and $2 \%$ of non-medullary carcinomas [4].

The indications for a radical mastectomy are identical and based essentially on tumor size ( $>$ or equal to $3 \mathrm{~cm}$ ) [2]. It is accepted that CM usually have less axillary lymph node involvement than other carcinomas $[3,9]$. In the CM family, the typical appears to cause less ganglionic metastases than the atypical. This ganglionic invasion is variable according to the studies of 19 to $46 \%$, with an attack of less than 4 ganglia [1,4]. Axillary management has changed considerably since the beginning of the 2000s with the introduction of the sentinel lymph node procedure. After this major evolution in case of T1-T2N0 Breast Cancer reducing the morbidity of the axillary surgical procedure, the maintenance of complementary axillary dissection in case of metastatic sentinel lymph node seemed indisputable [10].

The indications for CMR RTH are identical to other carcinomas [2]. Fisher et al. [11] showed that irradiation of the wall after mastectomy or breast after lumpectomy reduced the risk of local recurrence from $39 \%$ to $14 \%$. Adjuvant chemotherapy is indicated in cases of $\mathrm{N}+$ and in $\mathrm{N}$ - patients with poor prognosis factors (negative hormonal receptors, young age, tumor size greater than or equal to $3 \mathrm{~cm}$ ) (4.9). In neoadjuvent, it is indicated in case of T4 tumor or bulky tumor not accessible to a conservative treatment from the start. Protocols based on anthracycline (Doxorubicin or Epirubicin) seem to be the most suitable. There is no study on new drugs, especially Taxanes. Hormone therapy essentially uses the anti-estrogen. The authors consider the steroid receptors as a prognostic factor, which has a significant impact on the therapeutic outcome in case of CM; therefore, patients with positive estrogen receptors have better survival than patients with negative receptors. 
Paradoxically, this tumor has a better prognosis despite the decreased frequency of positive steroid receptors. The medullary carcinoma is characterized by a better survival rate than the other mammary carcinomas, this is demonstrated in most of the studies, and more specifically for the typical form [1,4]. Pedersen [12] demonstrated that the prognosis is better in $\mathrm{N}-$ or $\mathrm{N}+<3$ patients compared to patients with more than 3 positive lymph nodes. Tumor size, in medullary carcinoma as in other histological types, is an important factor in the occurrence of metastases and relapses and is directly correlated with survival [3]. The appearance of distant metastasis is more common for atypical spinal cord carcinoma. According to Martinez et al. [13]. The 10year survival rate for medullary carcinomas compared to invasive ductal carcinoma up to $84 \%$. The metastatic sites are identical to the rest of the carcinomas, dominated by bone, lung, liver, brain [14].

\section{Conclusion}

The medullary carcinoma is a tumor that is characterized by epidemiological, clinical and radiological characteristics and pathological often aggressive, contrasting with its favourable evolution.

\section{References}

1. Ridolfi RL, Rosen PP, Port A, Kinne D, Mike V (1977) Medullary carcinoma of the breast: a clinicopathologic study with 10 year followup. Cancer 40: 1365-1385.

2. Consensus de Saint Gall 2013.

3. Inhye Park, Jiyoung Kim, Minkuk Kim, Soo Youn Bae, Se Kyung Lee, et al. (2013) Comparison of the Characteristics of Medullary Breast Carcinoma and Invasive Ductal Carcinoma. J Breast Cancer 16(4): 417425.
4. Rapin V, Contesso G, Mouriesse H, Bertin F, Lacombe MJ, et al. (1988) Medullary. breast carcinoma. A reevaluation of 95 cases of breast cancer with inflammatory stroma. Cancer 61(12): 2503-2510.

5. Chandrika, Permi HS, Kishan Prasad HL, Mohan R, Shetty KJ, et al. (2012) Synchronous bilateral medullary carcinoma of breast: is it metastasis or second primary J Cancer Res Ther 8(1): 129-131.

6. Matheus VS, Kestelman FP, Canella EO, Djahjah MCR, Koch HA (2008) Medullary breast carcinoma: anatomo-radiological correlation. Radiol Bras 41(6): 379-383.

7. Cho N, Oh Kk, Lee SI (2002) Medullary carcinoma of the breast: Sonographic features distinguishing it rom fibroadenoma. J Med Ultrasound 10: 191-196.

8. World Health Organization (1982) Histological typing of breast tumors. Tumor 68: 181.

9. A Yong Cao, Min He, Liang Huang, Zhi-Ming Shao, Gen-Hong Di (2013) Clinicopathologic characteristics at diagnosis and the survival of patients with medullary breast carcinoma in China: a comparison with infiltrating ductal carcinoma-not otherwise specified. World J Surg Oncol 11: 91.

10. E Barranger a, G Houvenaeghel b, JM Classe c (2013) Prise en charge axillaire dans le cancer du sein : enquete de pratique francaise. Gynécologie Obstétrique \& Fertilité 41(2013): 433-436.

11. Fisher B, Redmond C (1992) Lumpectomy for breast cancer: an update of the NSABP experience. National Surgical Adjuvant Breast and Bowel Project. J Natl Cancer Inst Monogr (11): 7-13.

12. Pedersen L, Zedeler K, Holck S, Schiodt T, Mouridsen HT (1995) Medullary carcinoma of the breast. Prevalence and prognostic importance of classical risk factors in breast cancer. Eur J Cancer 31A(13-14): 2289-2295.

13. Martinez SR, Beal SH, Canter RJ, Chen SL, Khatri VP, et al. (2011) Medullary carcinoma of the breast: a population-based perspective. Med Oncol 28(3): 738-744.

14.Vu-Nishino h, Tavassoli fa, Ahrens Wa, Haffty Bg (2005) Clinicopathologic features and long-term outcome of patients with medullary breast carcinoma managed with breast-conserving therapy (BCT). Int J Radiat Oncol BiolPhys 62(4): 1040-1047.

\section{Your next submission with Juniper Publishers will reach you the below assets}

- Quality Editorial service

- Swift Peer Review

- Reprints availability

- E-prints Service

- Manuscript Podcast for convenient understanding

- Global attainment for your research

- Manuscript accessibility in different formats

( Pdf, E-pub, Full Text, Audio)

- Unceasing customer service

Track the below URL for one-step submission https://juniperpublishers.com/online-submission.php 